Revista de Derecho

de la Pontificia Universidad Católica de Valparaíso XXXIII (Valparaíso, Chile, ${ }^{\text {do }}$ Semestre de 2009)

[pp. 599 - 619]

\title{
LA OBJETIVIDAD DEL DERECHO \\ COMO FUNCIÓN DE LA SUBJETIVIDAD/OBJETIVIDAD DEL JUEZ*
}

["The Objectivity of the Law as a Function of the Subjectivity/Objectivity of the Judge"]

\author{
Cristóbal OrRego SánChez** \\ Universidad de los Andes, Chile
}

\begin{abstract}
RESUMEN
El artículo expone el intento de la teoría analítica del Derecho de describirlo objetivamente tal y cómo es. Explica por qué fracasa a lo largo del siglo XX. Se expone la analogía de la objetividad, para argumentar que el Derecho puede ser objetivo en función de una subjetividad ordenada del juez, lo cual rompe la rígida oposición objetivo-subjetivo, siguiendo la propuesta de Robert Spaemann. En consecuencia, la Ciencia jurídica objetiva debe volver a incorporar los problemas
\end{abstract}

\begin{abstract}
The article puts forward the attempt of objectively describing the analytical theory of the Law just as it is. It explains why it fails along the $20^{\text {th }}$ century. The analogy of the objectivity is put forward to argue that the Law can be objective depending on a methodical subjectivity of the judge, which breaks the rigid objective-subjective opposition, following Robert Spaemann's proposal. Therefore, the objective juridical Science of Law must again incorporate the justice prob-
\end{abstract}

* Esta publicación se enmarca en un programa de investigación que ha tratado desde la evolución reciente de la teoría analítica del Derecho, especialmente por la incorporación del estudio de los principios en el razonamiento jurídico, hasta el problema más particular de cómo intervienen esos principios racionales y legales en la especificación y definición de los actos humanos para los fines del razonamiento práctico. Agradezco al Fondo Nacional de Ciencia y Tecnología de la República de Chile el apoyo que ha hecho posible esta publicación, especialmente a través del Proyecto FONDECYT No 1080680.

** Profesor de Filosofía del Derecho en la Facultad de Derecho de la Universidad de los Andes. Dirección postal: San Carlos de Apoquindo 2200, Las Condes, Santiago, Chile. Correo electrónico: corregos@googlemail.com y corregos@googlemail. com 
de la justicia de manera explícita, como han sugerido también Dworkin, Finnis y Alexy.

Palabras clave: Objetividad del Derecho - Razonamiento Jurídico - Juez - Teoría Analítica del Derecho. lems in an explicit way, as also suggested by Dworkin, Finnis and Alexy.

KEYwORDS: Objectivity of the Law Juridical Reasoning - Judge - Analytical Theory of Law.

\section{INTRODUCCIÓN}

La inquietud por la objetividad del Derecho es la otra cara de la moneda del problema del escepticismo ante las reglas, que constituye, por su parte, el punto de llegada del intento de describir objetivamente -científicamente- el Derecho tal como es con independencia de valoraciones subjetivas acerca del Derecho como debería ser. La empresa de describir un Derecho que está ahí, contemplándolo como conjunto de reglas que son objeto de especulación avalorativa, fracasó. De aquí podría seguirse que no cabe un conocimiento objetivo acerca de lo debido en las relaciones entre los hombres, que intentamos regular mediante reglas de creación humana, puesto que estas mismas reglas no pueden ser descritas de una manera unívoca en general, ni, menos aún, en los intentos de su aplicación. Sin embargo, cabe otra posibilidad, a saber, afirmar que no hay contraposición necesaria entre la subjetividad del hombre que razona prácticamente y la objetividad de las razones para la acción, sino que, por el contrario, una determinada subjetividad práctica es condición de posibilidad del conocimiento práctico objetivo. En el caso del Derecho, esa subjetividad es, paradigmáticamente, la del hombre que cumple el rol de juez, quien dice el Derecho autoritativamente en cada caso. "En eso consiste ser jurista: en la iuris dictio, en la declaración del Derecho, en discernir y pronunciar la sentencia que contiene el Derecho, lo que es justo"'. En consecuencia, la posibilidad de objetividad en el conocimiento del Derecho se resuelve en la posibilidad de que determinados seres humanos tengan su subjetividad bien ordenada respecto del fin para el cual hemos creado el Derecho. Tan objetivo será el Derecho cuan objetivos sean los jueces en el cumplimiento de su función de determinarlo, pues el juez es el paradigma del cual participa quienquiera que deba conocer el Derecho.

En este contexto, juez objetivo es lo mismo que juez que juzga de manera correcta, $y$, por ende, justa en un sentido absoluto -ajustada

${ }^{1}$ Javier HerVada, Lecciones propedéuticas de filosofía del Derecho (Pamplona, Eunsa, 1992), p. 75. 
a todas las razones para sentenciar- o en un sentido relativo -ajustada solamente a las razones permitidas por las restricciones institucionales del sistema jurídico-político-. Se entiende, pues, que la misma tradición de pensamiento jurídico que tanto se empeñó en describir el Derecho objetivamente con independencia de la subjetividad judicial -la teoría analítica del Derecho- se haya abocado en las últimas décadas a estudiar el razonamiento jurídico, es decir, el punto de confluencia entre la objetividad del Derecho general y la objetividad prudencial de la respuesta a los casos concretos de conocimiento jurídico práctico. Los aportes recientes de la analítica al tema del razonamiento jurídico no son meramente descriptivos de la práctica judicial, sino que también la orientan hacia la determinación del Derecho justo.

La pretensión de objetividad cuasiontológica en el conocimiento del Derecho - del concepto de Derecho y de la realidad jurídica considerada como ser normativo en sí- ha dado paso al anhelo de objetividad práctica en la determinación del Derecho justo. Esta evolución de la teoría analítica puede comprenderse en tres etapas. Vamos a considerar primero el planteamiento especulativo de la teoría descriptiva del Derecho, desvelando las motivaciones prácticas que permiten comprender su sentido y el porqué de la evolución desde un escepticismo normativo parcial hacia el escepticismo normativo total. En segundo lugar, procuraremos presentar la analogía del concepto de objetividad y los tipos de saber objetivo según los sentidos de dicha analogía. De esta manera podremos afirmar, en tercer lugar, la objetividad del Derecho - del saber acerca del Derecho- en un cierto sentido, sin pretender concebirla ad imaginem de las ciencias especulativas. Se verá entonces que la objetividad propia del Derecho no puede entenderse como ajena a cualquier tipo de subjetividad humana. Es posible constituir un Derecho objetivo solamente mediante la adecuada ordenación de esa subjetividad, especialmente de la del juez. Rompemos así con la oposición objetivo/subjetivo propia de la modernidad filosófica. Las tres etapas de esta exposición culminan en la constatación de que el análisis teórico-práctico del razonamiento jurídico, tal como se ha ido imponiendo en la analítica contemporánea, está necesariamente orientado hacia la determinación del Derecho justo ${ }^{2}$. En consecuencia, la única forma de satisfacer las necesidades prácticas de la primera teoría analítica -las motivaciones que la habían llevado a buscar un análisis no valorativo del fenómeno jurídico- es abordar, como parte de un mismo

${ }^{2}$ Me remito, para esta evolución, a Cristóbal OrRego, De la ontología del Derecho al Derecho justo. Progresos recientes de la teoría analitica del Derecho, en Revista Chilena de Derecho 30 (2003) 2, pp. 307-320 
saber jurídico -en todos sus niveles de generalidad o concreción-, los problemas de la justicia y de su fundamento en la razonabilidad práctica general, como han hecho, cada uno a su manera, Ronald Dworkin, John Finnis y Robert Alexy.

\section{TEORÍA ANALÍTICA AVALORATIVA: EL SENTIDO PRÁCTICO DE UN SABER DESCRIPTIVO DEL DERECHO}

Desde Bentham y Austin en Inglaterra y la Escuela de la Exégesis en Europa, la ciencia jurídica se constituyó como ciencia de un tipo particular de hecho social, el Derecho considerado como conjunto de normas reguladoras de la vida social, originadas en alguna fuente social autoritativa. A esta orientación de la ciencia jurídica se la denominó, generalmente, "positivismo jurídico", por su semejanza con el positivismo científico, que pretendía conocer objetivamente el mundo natural ateniéndose a hechos empíricos y dejando de lado las oscuras lucubraciones metafísicas. En el caso del estudio del Derecho, lo que molestaba a los científicos como Bentham era la continuada confusión entre lo que el Derecho positivo establecía y lo que cada jurista -cada abogado en el foro-favorecía como ideal de justicia. Según Hart, "Bentham pensaba que la confusión se había extendido en dos direcciones diferentes. Por una parte, Bentham tenía en mente al anarquista que razona así: 'Esto no debe ser Derecho, por lo tanto no lo es, y soy libre no solamente para censurarlo, sino para ignorarlo'. Por otro lado, pensaba en el reaccionario que argumenta: 'Esto es el Derecho, por lo tanto es lo que debe ser', y así suprime la crítica en su nacimiento. Los dos errores, pensaba Bentham, podían encontrarse en Blackstone: estaba su incauta afirmación de que las leyes humanas eran inválidas si contradecían la ley de Dios, y 'ese espíritu de quietismo obsequioso que parece constitutivo de nuestro autor' que 'apenas le permitirá reconocer alguna vez una diferencia' entre lo que es y lo que debe ser. [...] Hay, pues, dos peligros que la insistencia en esta distinción nos ayudará a evitar: el peligro de que el Derecho y su autoridad puedan disolverse en las concepciones del hombre acerca de lo que el Derecho debe ser, y el peligro de que el Derecho existente pueda suplantar a la moral como criterio definitivo de conducta y escapar así a la crítica”"

Se imponía, pues, un estudio "objetivo" del Derecho "tal como es", de acuerdo con los hechos objetivos de su establecimiento -en la teoría voluntarista, las manifestaciones de la voluntad soberana-, y con indepen-

${ }^{3}$ H. L. A. Hart, Positivism and the Separation of Law and Morals, en Essays in Jurisprudence and Philosophy (Oxford, Oxford University Press, 1982), pp. 49-87, en pp. 53-54. 
dencia de lo que cada uno pudiera estimar que sería más justo, es decir, con independencia del Derecho "como debe ser" según diversas pautas variables de valoración (la moral, la ley de Dios, etc.).

Se ha de notar que algunos autores creían en la objetividad del conocimiento moral (v.gr., mediante un cálculo felicitario igualmente científico, en el caso de Bentham). Sin embargo, todos reconocían la división de los hombres por razón de sus ideales de justicia, ya por entonces evidente. Bajo el ideal de una ciencia jurídica aséptica subyacía la necesidad de evitar que cada uno obedeciera sus ideales de justicia como si fuesen el verdadero Derecho común a todos. De ahí el lema benthamiano: "obedecer puntualmente, criticar libremente". No puede extrañarnos, pues, que diversos autores, ya en pleno siglo XX, como Kelsen, Ross y Bobbio, estimaran que la necesidad de una ciencia positivista del Derecho se fundaba en la relatividad de los valores morales, i.e. en el no cognitivismo ético. Sea como fuere, el ideal de ciencia del Derecho - de conocimiento objetivo del Derecho que es- exige dejar fuera las valoraciones morales de quienes la practican: describir sin valorar. Supone, además, que el Derecho es objetivo como cualquier otro hecho susceptible de conocimiento científico, y que la ciencia del Derecho es objetiva correlativamente por la capacidad de la razón humana para conocer esos hechos constitutivos del Derecho o de darles una forma objetiva en el sistema científico.

Se puede caracterizar esta situación como la de un escepticismo normativo parcial. En efecto, se estima que las normas del Derecho son objeto de una ciencia rigurosa -la ciencia jurídica-, capaz de describirlas en cuanto normas objetivas de conducta, las cuales pueden, por ende, ser seguidas por los seres racionales con prescindencia del desacuerdo moral entre ellos. En cambio, el conocimiento del orden moral es de suyo discutible -relativo a una adopción subjetiva de valores últimos, o simple expresión de emociones objetivadas en un lenguaje enmascarador, o lo que sea-, y su carácter no cognitivo -en cualquiera de sus formasamenaza con contaminar toda la ciencia jurídica objetiva si acaso los dos campos llegaran a confundirse. Incluso quien aceptase la posibilidad de una ciencia ética objetiva -tanto como la ciencia jurídica, pero referida a otros "hechos" - tendría que prescindir de ella para poder cultivar una ciencia jurídica objetiva que fuese válida tanto para sí mismo como para otros que de hecho no compartieran las mismas convicciones morales. El hecho del desacuerdo moral y la imposibilidad de su evitación mediante procedimientos especulativos exigen, con independencia de la opinión de cada jurista acerca de si la moral es objetiva o no, actuar como si no lo fuera y atenerse a los hechos del Derecho tal como es. La ciencia jurídica 
es posible de manera unitaria siempre que se separe de la ciencia moral, sea o no ésta también objetiva.

Hasta aquí parece que la justificación de la teoría jurídica analítica no valorativa -la empresa descriptiva del Derecho que es- es solamente el ideal decimonónico de ciencia, más allá de una conexión de la ciencia con la política y la ética. Se trata precisamente de negar tal conexión. Sin embargo, bajo esta concepción especulativa de la ciencia jurídica y de la teoría del Derecho subyace una justificación política y ética. Hobbes había visto con claridad la necesidad de atenerse a los mandatos del soberano para tener una regla clara de lo justo -la ley estatal- y evitar la anárquica guerra de todos contra todos. Bentham tuvo en vista similares consideraciones prácticas. Aunque en el siglo XX los juristas positivistas, especialmente Kelsen, presentaron la necesidad de separar el Derecho que es de cualquier ideología moral o política solamente como una exigencia de rigor científico, la pasión que pusieron en el intento nos mueve a examinar sus motivos más profundos.

Los juristas continentales del siglo XIX tenían claramente un fundamento político para su teoría positivista del Derecho: asegurar la división de poderes, dando la primacía absoluta al legislador y dejando a los jueces una función residual, que se concebía como "mera aplicación" de las leyes. La misma mentalidad empapó la labor de los jueces en Estados Unidos -a pesar de proceder de un sistema de Derecho común jurisprudencial-y en otros países de América, dando origen a lo que despectivamente llegó a llamarse "positivismo legalista" o -en palabras de Pound- "jurisprudencia mecánica” . Esta actitud se fundaba en una justificación política plenamente consciente en sus comienzos, nada menos que la separación constitucional de los poderes 5 .

Más tarde, la conexión ético-política fue perdiéndose de vista. Hans Kelsen, H. L. A. Hart y todos los positivistas posteriores rechazaron esa imagen "legalista" o "mecánica" como simplemente inadecuada desde el punto de vista de una teoría general descriptiva del Derecho. Sin embargo, subsistió alguna justificación práctica del empeño descriptivo avalorativo. Se trataba de conseguir seguridad jurídica, de saber a qué atenerse, de poder seguir concibiendo el Derecho como la empresa normativa de

${ }^{4}$ Cfr. Roscoe Pound, Mechanical Jurisprudence, en Columbia Law Review 8 (1908), pp. 605 ss. Se trata del cuarto significado de "positivismo jurídico" en la clásica enumeración de H. L. A. HART, The Concept of Law (Oxford, Clarendon Press, 1961), p. 253.

${ }^{5}$ Para una descripción de la actitud legalista y de la ideología a ella subyacente, véase: Chäim Perelman, La lógica jurídica y la nueva retórica (Madrid, Civitas, 1979), pp. 35-71. 
sujetar a los hombres a criterios comunes de comportamiento. Es verdad que, desde que el ataque político contra el positivismo jurídico lo sindicó como responsable de la obediencia puntual a normas inicuas (i.e., la reductio ad Hitlerum), se añadió una justificación práctica de signo contrario: la necesidad de identificar claramente el Derecho inicuo para poder resistirlo con plena conciencia de lo que se hacía: "Deberíamos decir: 'Esto es Derecho; pero es demasiado inicuo para ser aplicado u obedecido"'6. Esta última justificación, sin embargo, nunca ha sido realmente asumida en la cultura jurídica positivista, sino que parece una defensa $a d$ hoc frente a la acusación de complicidad con la injusticia. De hecho, siempre que hay un debate moral en las sociedades pluralistas, ya sea sobre qué debe hacerse en general o sobre cómo interpretar normas legales establecidas, se vuelve a la idea antigua de que el Derecho positivo establece lo debido en común para todos, con independencia de las ideas morales de cada uno. Tal es la tesis de que la necesidad práctica que el Derecho satisface es la seguridad jurídica, el saber a qué atenerse. Esto supone que el Derecho que es tiene una realidad propia, independiente de las subjetividades de los hombres, y que la ciencia jurídica es, correlativamente, un tipo de saber objetivo.

Ahora bien, la justificación práctica de la ciencia jurídica descriptiva -saber a qué atenerse, considerar el Derecho como algo que realmente mueve a los hombres- explica la multitud de posiciones acerca del concepto de Derecho positivo. Si se trata de describir el Derecho que es - una especie de objeto en sí, bien que no natural sino construido por los hombres mediante hechos empíricos-, se plantea el problema de seleccionar el objeto para poder, luego, describirlo. No basta con la respuesta negativa: el Derecho que es es distinto del Derecho que debe ser, según una pauta externa de valoración. Kelsen y los autores más cercanos a la tradición de la antigua ciencia normativa del Derecho siguieron pensando en la objetividad del mundo normativo, es decir, en el Derecho como conjunto de normas o de reglas creadas por la voluntad humana como un medio de control social. De esta manera, la ciencia del Derecho tenía como misión esencial describir normas y determinar su existencia por su relación con actos voluntarios de creación de normas. Se puede decir, en este contexto, que la ciencia jurídica es objetiva porque hay normas realmente aptas para guiar las conductas de funcionarios y de ciudadanos, normas que existen a su vez objetivamente porque hay actos empíricos que crean esas normas (mandatos de la voluntad en la teoría imperativa o prácticas y actitudes racionales críticas en la teoría no imperativa de Hart). Naturalmente, los autores que anclan el Derecho como norma en hechos empíricos -prác-

${ }^{6}$ H. L. A. Hart, The Concept of Law (cit. (n. 4), p. 203. 
ticas, actos de voluntad de los funcionarios, etc.- intentan por diversos medios salvar el abismo de la "ley de Hume" o mantener un paralelismo no inferencial entre hechos y normas, pero ponen en peligro el carácter objetivo de la normatividad, especialmente en el caso de Kelsen, quien la reduce a una hipótesis primero y a una ficción más tarde 7 .

Sea como fuere, la objetividad del mundo normativo está en peligro como genuino objeto representativo del Derecho que es, en la medida en que la dicotomía ser/deber o hecho/norma conduce a fijar la atención solamente en aquello que puede ser comprobado mediante los instrumentos de las ciencias empíricas, considerando todo el mundo del "deber ser" como mera ficción o ilusión "metafísica". Además, si volvemos a considerar la tácita justificación práctica del intento de conocer asépticamente el Derecho "que es" -i.e., saber a qué atenerse, seguridad jurídica, unidad de las pautas de conducta para personas de diversas convicciones morales-, los diversos tipos de realismo o de empirismo jurídico tienen adecuadas pretensiones de ser más descriptivos del Derecho real: lo que decidirán los jueces, lo que realmente pasará si se desobedece una norma general, lo que le interesa al hombre malo (Holmes), la probabilidad empírica de sanción coactiva -no el mero "deber" normativo de que un funcionario la imponga-. Si, por ejemplo, uno evade la mitad de sus impuestos y nunca le sucede nada, ¿cuál es el Derecho que es, la norma abstracta que dice que debería ir a la cárcel o la constatación empírica de que los jueces no lo mandan a la cárcel? La norma general no es el Derecho que es, sino el Derecho que debería ser según el legislador y su finalidad práctica -sus intentos de recaudar más-; pero una cosa es el Derecho que debería ser -lo que el recaudador querría recaudar, el castigo que él querría aplicar a los evasores- y otra el Derecho que realmente es, lo que realmente se le impone al ciudadano desobediente. A fin de cuentas, si se trata de saber a qué atenerse y de conocer "científicamente" un Derecho como "hecho" independiente de valoraciones subjetivas, las reglas generales son sólo relativamente relevantes.

${ }^{7}$ La última explicación de Kelsen puede verse en Hans Kelsen, Teoría general de las normas (traducción castellana de Hugo Carlos Delory Jacobs, México D.F., Trillas, 1994), cap. 59, pp. 248-252.

${ }^{8}$ Véanse, entre otras exposiciones: Ross, Alf, El concepto de validez y el conflicto entre el positivismo jurídico y el Derecho natural, en Ross, Alf, El concepto de validez y otros ensayos (México, D.F., Fontamara, 1993), pp. 9-32, y su intento de disolver completamente el dualismo validez/hechos en la ciencia jurídica: Ross, Alf, Hacia una ciencia realista del Derecho. Crítica del dualismo en el Derecho (trad. cast. de Julio Barboza, Buenos Aires, Abeledo-Perrot, 1961), especialmente 15-23, 40-57 y 114121. 
Tal era el punto muerto al que había llegado la teoría analítica del Derecho alrededor de los años 60 del siglo pasado. Podría decirse que el ideal de un Derecho objetivo y de una verdadera ciencia objetiva del Derecho estaba en crisis, y que del escepticismo normativo parcial se estaba llegando a un escepticismo normativo total. Kelsen y Hart no eran más que intentos de preservar el ideal decimonónico de ciencia jurídica, relativizado por la aceptación de la discrecionalidad judicial, en un contexto de evidente escepticismo normativo en las sociedades posmodernas y pragmatistas.

El poderoso intento de H. L. A. Hart de construir una teoría equilibrada, alejada del normativismo puro de Kelsen y del completo escepticismo ante las reglas, se basaba en un rescate del carácter racional de las reglas generales, es decir, en su rechazo de la teoría imperativa del Derecho que había dominado las ciencias normativas (ética, política y Derecho) durante aproximadamente cuatro siglos ${ }^{9}$. Hart, aun conservando la separación supuestamente positivista entre Derecho y moral, desligó la descripción aséptica del Derecho de la cuestión política clave que le había dado origen: el problema de la obediencia: "hay algo fuera del sistema oficial por referencia a lo cual el individuo debe resolver, en última instancia, sus problemas de obediencia" ${ }^{10}$. Para saber a qué atenerse, para el problema de la obediencia, sería necesario volver a recurrir a fuentes ajenas al sistema normativo jurídico. Incluso los jueces, para decidir adecuadamente conforme a Derecho, tienen que ejercer una discreción no irracional, sino guiada por principios ${ }^{11}$. Además, la determinación general de los fundamentos del sistema de reglas depende del conjunto de prácticas de los funcionarios -especialmente de los jueces- y de su actitud interna: las reglas de reconocimiento. En consecuencia, desde mediados del siglo XX se instala un paradigma de conocimiento jurídico objetivo en el que comienza a tener cada vez mayor importancia la judicación -la determinación de lo debido en cada caso, aunque se utilicen las reglas generales como pautas orientadoras- y el uso de razonamientos orientados por principios, sin abandonar por eso la sujeción de los jueces a

${ }^{9}$ La explicación del Derecho y de la normatividad en general ha fluctuado entre el voluntarismo y el racionalismo. La posición equilibrada de Tomás de Aquino concede prioridad al carácter racional de las normas, sin desconocer la intervención de la voluntad. Véanse: HeRVADA, Javier, Lecciones propedéuticas de filosofia del Derecho, cit. (n. 1), pp. 330-362; y FinNis, John, Ley natural y derechos naturales (traducción castellana de Cristóbal Orrego (Buenos Aires, Abeledo-Perrot, 2000), pp. 362-367 у $373-376$.

${ }^{10}$ Hart, H. L. A., The Concept of Law, cit. (n. 4), p. 206, énfasis añadido.

${ }^{11}$ Hart es explícito en este punto, aunque no lo haya desarrollado: las críticas de Dworkin son exageradas. Cfr. HART, H. L. A., Post scriptum al concepto de Derecho (editado por Penelope A. Bulloch y Joseph Raz, trad. cast. de Rolando Tamayo y Salmorán, México, D.F., UNAM, 2000), pp. 42-43. 
las leyes. Esta evolución intelectual ha ido acompañada por la apertura de los sistemas jurídicos normativos a la incorporación explícita de criterios morales (dignidad de la persona, derechos humanos, valores como la justicia o la igualdad, etc.), y por la ampliación de los poderes judiciales que dicha incorporación implica, pues todos esos conceptos morales requieren de concreción jurisprudencial. Ya no puede decirse científicamente cuál es el Derecho que es sin atender a una gran pluralidad de fuentes sociales -no solamente las leyes escritas- y sin intentar incluso prever los razonamientos prácticos y las valoraciones morales de los funcionarios, es decir, sus concepciones sobre el Derecho que debe ser.

La objetividad del Derecho que es depende de que haya parámetros objetivos de decisión judicial, los cuales sólo parcialmente pueden contenerse en reglas que sean, a su vez, generales. En efecto, una regla no puede aplicarse a sí misma, y las reglas para aplicación de reglas requieren, a su vez, de interpretación humana. En consecuencia, el ideal ilustrado de un Derecho igual para todos -que, a su manera, forma parte de la idea clásica de justicia: lo justo es lo igual con analogía de proporcionalidad-y de una ciencia jurídica objetiva, una vez que se abandona la ingenua creencia en un saber absoluto o en una razón desconectada de las concretas condiciones históricas de los seres humanos y de sus comunidades, solamente es posible mediante la existencia de juristas que encarnen de alguna manera el ideal de la objetividad. La objetividad no es una simple condición deseable del conocimiento científico, sino un ideal ético-político que han de realizar personas de carne y hueso.

El problema, para algunos angustioso, de la objetividad del Derecho y de la ciencia jurídica ha oscilado entre el extremo de la creencia irracional en la objetividad de una normatividad abstracta y en la capacidad de la razón humana para operar sin prejuicios y el no menos irracional extremo del escepticismo, que desconoce la realidad empírica de millones de seres humanos efectivamente coordinados entre sí merced a decisiones generales adoptadas por muy pocos, seguidas generalmente sin indicaciones particulares ulteriores y sin cálculos de probabilidades de castigo, y efectivamente impuestas mediante funcionarios en los casos de conflicto, que son comparativamente minoritarios.

La teoría jurídica analítica post-hartiana ha enfrentado el problema rechazando los dos extremos y desarrollando reflexiones particulares sobre los obstáculos que impiden confiar equilibradamente en una objetividad jurídica posible: i) la relación entre Derecho y moral -replanteando las tesis positivistas una vez más $-^{12}$; ii) la vaguedad en el Derecho y las ana-

${ }^{12}$ Este replanteamiento ha dado origen al debate -casi puramente nominal- en- 
logías entre el Derecho y otras formas de vida según reglas y principios y sus aplicaciones ${ }^{13}$; iii) la función de los principios en la orientación del razonamiento judicial ${ }^{14}$; y iv) el carácter revocable o derrotable de las reglas propiamente jurídicas ${ }^{15}$. En todos estos desarrollos está presente, de alguna manera, el redescubrimiento hartiano del Derecho como un tipo de razón -no un mero reflejo de actos de voluntad, mandatos, etc.-, de manera que la cuestión de la objetividad del Derecho y de la ciencia jurídica puede replantearse adecuadamente: i) como una cuestión particular sobre los modos de objetividad de la razón, que no se limita a describir lo que es como objeto de especulación; y ii) como una cuestión sobre la relación entre la objetividad del Derecho en cuanto medida común para muchos y la subjetividad de los jueces en cuanto personas-instituciones encargadas de hacer real esa medida común.

\section{ANALOGÍA DE LA OBJETIVIDAD: EL SABER PRÁCTICO OBJETIVO Y SUS OBJETIVACIONES EMPÍRICAS}

Normalmente decimos que algo es “objetivo" en cuanto que está ahí frente a nosotros (i.e., es real o verdadero en sí), pero reconocemos la limitación de nuestro conocimiento y, por ende, que lo objetivo no es

tre positivismo jurídico incluyente y positivismo jurídico excluyente. Cfr. Andrei Marmor, Exclusive legal positivism, en Coleman, Jules - Shapiro, Scott (editores), The Oxford Handbook of Jurisprudence and Philosophy of Law (Oxford, Oxford University Press, 2002), pp. 104-124; y Hiмма, Kenneth Einar, Inclusive legal positivism, ibíd., pp. 125-165.

${ }^{13}$ Véanse las exposiciones de: EndicotT, Timothy, Law and Language, en ColeMAN, Jules - SHAPIRO, Scott (editores), The Oxford Handbook cit. (n. 12), pp. 935968; y Brian LeITER, Law and Objectivity, ibíd., pp. 969-989. Constituye una sorprendente carencia de rigor intelectual, en esta última exposición, la de Leiter, no haber tenido en cuenta ninguna de las explicaciones clásicas sobre la "objetividad" del Derecho anteriores al siglo XX. Para un complemento véase la renovada presentación de FinNIs, John, Ley natural y derechos naturales, cit. (n. 9), pp. 110-111 y 294-301; y Finnis, John, Natural Law: The Classical Tradition, en Coleman, Jules - SHAPIRO, Scott (editores), The Oxford Handbook, cit. (n. 12), pp. 1-60, en 39-40.

${ }^{14}$ Un panorama de esta evolución, centrado en Dworkin y Alexy mas no limitado a ellos, en García Figueroa, Alfonso, Principios y positivismo jurídico. El no positivismo principialista en las teorias de Ronald Dworkin y Robert Alexy (Madrid, Centro de Estudios Políticos y Constitucionales, 1998), pp. 27-216. La expresión "no positivismo" es el circunloquio actualmente en uso para afirmar-sin regresar a la nomenclatura antigua- que el positivismo jurídico erró en su crítica a la tradición iusnaturalista. Por mi parte, siempre he seguido el lema de nominibus non est disputandum.

${ }^{15}$ Cfr. la discusión de Atria, Fernando, On Law and Legal Reasoning (Oxford, Hart Publishing, 2001), pp. 123-140. 
todo lo real, sino aquellos aspectos de lo real que se conmensuran con nuestro conocimiento. Así, el conocimiento es propiamente "objetivo" porque se corresponde con algo de lo real sin sufrir la distorsión de nuestra subjetividad, salvo la limitación inevitable de nuestros modos de conocer. Por eso decimos que una persona es "objetiva" cuando sus juicios y sus razonamientos no se desvían de la realidad por sus pasiones, sus intereses o su mala voluntad. Así, por ejemplo, cuando necesitamos un consejo acudimos a alguien objetivo en este sentido, y del mismo modo queremos que nos juzguen jueces objetivos. De manera que el ser objetivo es un modo de ser de la subjetividad humana.

La noción de objetividad es analógica porque se predica de diversas realidades según diversos modos de relacionarse nuestra razón con ellas. El error fundamental de la teoría ética y jurídica moderna consistió en buscar una objetividad especulativa en el conocimiento del Derecho (i.e., teórica, propia de las ciencias naturales y matemáticas), para, una vez fracasado el intento de una tal ciencia jurídica objetiva, caer en el escepticismo, sin reparar en que hay otras formas de objetividad. En la teoría analítica reciente, John Finnis ha rescatado la explicación cuatripartita de Tomás de Aquino sobre los diversos órdenes de la realidad, todos ellos objetivos, pero de diversa manera. El saber práctico jurídico y los saberes jurídicos teórico-prácticos se sitúan dentro de uno de los órdenes objetivos, pero la objetividad del Derecho no puede ser separada de la objetividad de personas concretas que crean y mantienen ese orden.

La razón se relaciona con la realidad (en sentido amplio) de cuatro modos diversos, que dan origen a cuatro órdenes en los que puede dividirse todo lo real y todos los modos de conocer-ordenar la realidad. Hay un orden que la razón humana solamente contempla, pero no produce (orden 1). Se trata del orden de las realidades naturales, del ente en sí mismo, que el ser humano encuentra como una evidencia primaria. El conocimiento de este orden compete a la sabiduría especulativa o teórica, a las ciencias teóricas, etc. Los otros órdenes de la realidad son producidos por la razón humana.

Existe un orden que la razón introduce en su propio acto al considerarlo, para dirigirlo de tal manera que cumpla efectivamente su fin, el fin de la razón humana (orden 2). La razón humana tiene por fin conocer la verdad especulativa y realizar la verdad práctica. Puesto que el orden de la realidad en sí, que es objeto del conocimiento especulativo, y la ordenación a los fines humanos, que es el objeto del saber práctico, requieren el ejercicio de la razón (especulativa o práctica), la razón necesita estar ella misma en sí misma ordenada, bien dispuesta, para el logro del saber respecto de esos otros órdenes. En consecuencia, la razón se ordena a sí misma. El 
saber práctico que versa acerca de la razón misma y del orden necesario en su propio acto de razonar para el adecuado logro del conocimiento teórico y práctico se denomina Lógica. La Lógica ha sido considerada como arte -el arte de pensar y de relacionar los conceptos en el sistema científico- y como filosofía racional -la parte de la filosofía que se ocupa de los entes de razón, creados por el entendimiento humano para poder asir y relacionar en la mente los objetos del conocimiento especulativo y práctico. Puede verse que la razón crea, efectivamente, unos entes -un orden de la "realidad"- que no son realmente reales, sino "ideales" (entes de razón). Sin embargo, si el fin por el que la razón crea entes de razón es el conocimiento de lo que es en sí y la ordenación práctica de los actos humanos (órdenes 3 y 4 , a los que nos referiremos en breve), es evidente que el orden de la Lógica depende del orden de la realidad que la razón no crea sino que contempla y de las realidades prácticas ordenadas a los fines humanos. De lo dicho se sigue que el orden lógico, producido en la razón humana por la razón humana, puede llamarse "subjetivo" en cuanto que se da en un sujeto humano, y sin la subjetividad humana, en que reside, ese orden no tiene realidad ninguna (como veremos, todo orden práctico existe sólo después del acto de la razón). En cambio, si por "subjetivo" se entiende lo que depende de la voluntad o de la decisión libre de un sujeto, el orden de la lógica no es subjetivo. Por el contrario, es tan objetivo que si no existe según las exigencias de esos otros órdenes a cuyo conocimiento y realización se ordena, no existe en absoluto. En el lenguaje corriente se dice que hay personas que son "más lógicas" que otras, es decir, que tienen sus ideas más ordenadas interiormente y la misma capacidad de ordenar sus actos racionales y sus objetos, lo cual les facilita el ejercicio de la razón para conocer la realidad - proceder con orden y sin error en la contemplación, descubrimiento, descripción, etc., de lo que existe en sí- y el ejercicio de la razón práctica.

Existen dos órdenes de la "realidad" que afectan a los actos humanos. Hay un orden que la razón humana introduce en el acto de la voluntad (orden 3) al considerarlo para dirigirlo a algún fin humano, es decir, a la realización de un aspecto del bien de la persona que obra. Este orden es introducido por la razón en la acción voluntaria, de manera que la acción humana adquiere un orden cuando procede de la elección precedida de una deliberación racional. El orden es introducido por la razón que dirige el obrar hacia los fines, fines que hacen inteligible la acción y determinan el orden. De esta parcela de la "realidad" -un orden creado o introducido por la razón humana en el acto de la voluntad- se ocupa la filosofía práctica y, en general, todo saber sobre los objetos operables propios de la acción humana libre, la ciencia jurídica entre otros. Las "realidades" 
constituidas por la razón para ordenar actos voluntarios hacia sus fines son reglas de la acción, orientaciones de la acción, órdenes racionales de conducta, $y$, como tales, tienen su ser solamente en la mente de quienes ordenan y de quienes son ordenados. De aquí que la ética, la política y el Derecho, tienen este tipo de objetividad. Puede decirse que este tercer orden es algo "subjetivo", en el sentido de que existe en la mente y no como objeto de contemplación; pero, por depender de la razón que busca los bienes humanos, este orden es plenamente "objetivo" en la medida en que realmente dirige las acciones hacia esos fines, y en la medida en que hay algunos objetos realmente buenos para todos los hombres, percibidos por la razón práctica como fines últimos de las acciones ${ }^{16}$. En atención a que los medios y los modos de realización del bien humano son múltiples y variados, y no están definidos racionalmente a priori, este orden objetivo puede constituirse con una gran libertad creativa, que da origen a muchas culturas y sistemas jurídicos diversos. Sin embargo, la ética puede discernir algunos intentos de plasmar este orden como contrarios al bien humano, y entonces los califica de injustos o moralmente malos: son objetivamente malos porque el orden racional es interferido por alguna desviación de la voluntad.

Desde el punto de vista de cómo se relaciona la razón con el orden existe un orden que la razón humana introduce en los actos exteriores en cuanto producen un efecto externo (orden 4), es decir, un orden que imponemos a lo que está materialmente sometido a nuestro poder para "crear" artefactos (ruedas, automóviles, computadores, esculturas, música, casas, alimentos, etc.). De este orden se ocupan las "artes", las "técnicas", las "ciencias aplicadas", etc., es decir, todos los saberes "prácticos" cuyo fin no es el bien de la persona que obra (propio del orden 3) sino la realización externa. Para evitar equívocos, en este caso algunos hablan, más que de saber práctico a secas, de diversos saberes "técnicos", "artísticos" o "poiéticos", el saber hacer bien cosas exteriores. Nuevamente hay que decir que el orden de la técnica, introducido en el hacer exterior por la razón, es "subjetivo" en cuanto que no existiría si no hubiese sido inventado, creado, por la razón humana. Sin embargo, es plenamente "objetivo" en cuanto que está determinado por los fines exteriores a cuya consecución se ordena la realización externa. Así, por ejemplo, no existiría el "orden" de la fabricación de automóviles sin la "creación" por sujetos humanos; pero nadie podría crear un automóvil sin adaptar esa creación a un orden exigido tanto por las características del material que se utiliza (orden 1) como por la finalidad a la que se orienta el artefacto (v.gr., no se puede

${ }^{16}$ Cfr. FinNis, John, Ley natural y derechos naturales, cit. (n. 9), pp. 91-163. 
uno trasladar en un automóvil sin ruedas). El orden jurídico, existente primariamente como realidad mental de dirección de actos voluntarios, se plasma en realizaciones exteriores (técnicas) indispensables para mantenerlo como una realidad continuada, independiente de las mentes humanas que la realizan en el orden práctico de la acción voluntaria. En este sentido, muchos elementos de lo que normalmente describimos como Derecho (leyes escritas, sentencias, etc.) pertenecen al orden $4^{17}$.

Por lo dicho sobre los cuatro órdenes de la realidad, puede verse que lo único "real en si" con independencia de la existencia del ser humano es el orden 1 objeto de contemplación. Esta cuádruple división de todo lo real y de los saberes -teóricos y prácticos- que versan sobre lo real permite comprender del mejor modo la especificidad del saber práctico. No obstante, ha de tenerse en cuenta que la conexión de los cuatro órdenes y el carácter más fácilmente cognoscible de los órdenes 1 y 4, por su plasmación en lo sensible exterior que es objeto adecuado e inicial de todo conocimiento humano, aconsejan explicar también el orden 3 (práctico) con frecuentes analogías respecto de los órdenes 1 y 4 . Mas sería un error tomarse esas analogías al pie de la letra; pensar, por ejemplo, que la ley es esencialmente el texto escrito en un código, antes que su sentido racional en la mente ${ }^{18}$.

\section{LA OBJETIVIDAD DE LOS JUECES COMO CONDICIÓN DE LA OBJETIVIDAD DEL DERECHO}

De lo que hemos expuesto puede colegirse que la peculiar objetividad de lo jurídico no consiste en el "estar ahî" como objeto de contemplación -la objetividad de una cosa natural, propia de las ciencias especulativas, entre ellas, las ciencias empíricas-, aunque nada se opone al uso de métodos especulativos y empíricos para estudiar aspectos conexos con la

\footnotetext{
${ }^{17}$ Cfr. Finnis, John, Natural Law and Legal Reasonin", en George, Robert P. (editor), Natural Law Theory. Contemporary Essays (New York, Oxford University Press, 1992), pp. 134-157, en 141-143, donde Finnis considera el Derecho positivo como un complejo objeto cultural del cuarto orden. En mi exposición, sin negar esta objetivación del Derecho en el cuarto orden, considero primaria su objetividad como orden mental de dirección de las acciones voluntarias (i.e., en el tercer orden de objetividad), al que Finnis se refiere, ibíd., pp. 138-141.

${ }^{18}$ La exposición clásica de esta categorización de los órdenes objetivos de la realidad y del conocimiento se halla en Tomás DE AQuino, Comentario a la Ética a Nicómaco I, 1 (proemio). John Finnis, apoyándose en Grisez, Germain, Beyond the New Theism: A Philosophy of Religion (Notre Dame, Ind., Notre Dame University Press, 1975), explica los cuatro órdenes en FINNIS, John, Ley natural y derechos naturales, cit. (n. 9), pp. 166-169.
} 
realidad jurídica que se plasman en seres que están ahí (regularidades de comportamiento social, sentimientos de compulsión, artefactos del mundo 4 o técnicos, etc.). El orden jurídico, en cuanto creación humana social destinada a permanecer en el tiempo y a constituir estructuras de relación permanentes, necesita plasmarse, además, como hemos dicho, en realidades "fabricadas" por el hombre de acuerdo con un orden técnico: códigos, edificios de tribunales, etc. Sin embargo, las realidades técnicas asociadas con el Derecho no son más que objetivaciones empíricas de su realidad racional o bien instrumentos mecánicos de la acción humana exterior. La objetividad propia del Derecho pertenece al orden que la razón humana constituye para dirigir las acciones voluntarias hacia un fin común.

En consecuencia, la objetividad propia del Derecho no es ajena a toda subjetividad -entendida como ser mental de personas singulares-, sino que, por el contrario, presupone la subjetividad de la razón humana en cuanto constitutiva de la ordenación racional. Esta subjetividad de la razón puede contraponerse a la subjetividad de una voluntad arbitraria, y a la subjetividad de una razón particular desviada por el capricho o la pasión o el interés. En este último sentido, se distingue entre personas "objetivas" en sus juicios y razonamientos y personas "subjetivas" en sus juicios y razonamientos. Las dos clases de personas razonan y ejercen una potencia "subjetiva", y constituyen el orden racional del Derecho cuando tienen potestad o procuran interpretarlo y conocerlo para guiarse por él o para guiar a otros. Sin embargo, solamente las personas "objetivas" consiguen dar a ese orden que ellas crean, siguen, interpretan o aplican, una orientación hacia el bien de las personas ordenadas -hacia el bien común- y no solamente hacia el bien propio, parcial, sugerido por el interés, la pasión o el capricho.

El Derecho como orden de convivencia se concreta en las determinaciones judiciales de lo debido a cada uno en cada caso. Por ende, solamente los jueces “objetivos" -i.e., que apartan de sus decisiones judiciales el capricho individual, el interés o la pasión que impiden ver lo realmente debido en cada caso, de acuerdo con criterios supraindividuales y realmente comunes a todos los afectados, criterios públicos de decisión correcta ${ }^{19}$-pueden conocer el Derecho objetivo y concretarlo como realidad normativamente fundada. Fuera de las decisiones justas - entendidas en este sentido modesto:

${ }^{19}$ Esta idea procede de Hart, H. L. A., The Concept of Law, cit. (n. 4), p. 112, según el cual la regla de reconocimiento "debe ser considerada desde el punto de vista interno como una pauta común, pública, de decisión judicial correcta”. Añado yo que esta corrección exige, para que la pauta sea común, la corrección y la objetividad de los funcionarios, los jueces, quienes mediante su actitud interna y sus prácticas establecen las reglas de reconocimiento. 
ajustadas a lo debido según criterios públicos de corrección, que incluyen los criterios éticos cuando el Derecho positivo debe ser desobedecido-, de las decisiones no desviadas por la subjetividad irracional del juzgador, no existe el Derecho tal como es. De lo cual se sigue la importancia de conocer racionalmente el lugar, por decirlo así, donde se unen los criterios normativos abstractos y las determinaciones jurídicas concretas, es decir, el razonamiento jurídico, paradigmáticamente el del juez. La actividad judicativa deja de ser un ejercicio de subjetividad controlada, es decir, de discrecionalidad, aunque pueda caracterizarse así cuando se concibe el Derecho objetivo solamente como el conjunto de reglas generales de un sistema. La judicación, por el contrario, pasa a ser la actividad constitutiva del Derecho objetivo en su máxima realización. Esta actividad judicativa depende enteramente de que los jueces en general sean, más que técnicos de la aplicación de reglas, verdaderos virtuosos de la decisión correcta. Las virtudes del juez no son solamente especulativas, porque el juez debe estar bien dispuesto respecto de las materias y de las personas sobre las cuales decide. Debe ser un juez justo de acuerdo con la justicia legal y con las virtudes morales del juzgador: imparcialidad, sujeción a las leyes, independencia, claridad de criterios éticos sobre cada asunto, etc.

Éste es el contexto en el que, según me parece, puede apreciarse la necesidad práctica, de la reciente teoría jurídica analítica, de analizar el razonamiento jurídico y de proponer tesis no solamente descriptivas, sino también normativas. Subyace la necesidad que movía a la primera teoría analítica, la denominada "positivista": saber a qué atenerse, delimitar los criterios de decisión pública correcta. Pero, saliendo de la ingenua confianza en la razón aséptica, se reconoce ahora que dicha necesidad solamente puede servirse ocupándose de la corrección objetiva de los procesos decisorios, es decir, del análisis y orientación del razonamiento y de la argumentación respecto del Derecho. No desconozco que, en este intento, subsiste el no cognitivismo normativo, tanto respecto de las reglas generales del Derecho como respecto de los criterios morales que necesariamente intervienen en la judicación. Sin embargo, junto con expresiones de ese escepticismo normativo, encontramos el esfuerzo práctico por limitarlo o por acotarlo mediante una adecuada teoría de la argumentación o del razonamiento jurídico o de la continuidad entre las valoraciones morales y las determinaciones jurídicas. Este esfuerzo es señal de una confianza en la razón, que no es coherente con las declaraciones de escepticismo general.

Algunas aportaciones de la jurisprudencia analítica reciente han mostrado, pues, la necesidad de esta mejor comprensión del razonamiento jurídico, precisamente como garantía o, en mi opinión, como única manera de conseguir la objetividad del Derecho tal como es en definitiva. Así, Neil 
MacCormick vio necesario complementar el concepto de Derecho elaborado por Hart con su propia investigación sobre el razonamiento jurídico ${ }^{20}$. Dworkin, como había sucedido ya en el continente, muestra que en el Derecho tal como es intervienen principios no previamente explicitados en las reglas del sistema ${ }^{21}$. Los actuales iuspositivistas (incluyentes o excluyentes) coinciden en las consecuencias prácticas sobre cómo han de orientarse las decisiones de los jueces en relación con el Derecho positivo: deben aplicar las reglas fundadas en fuentes sociales autoritativas junto con las exigencias éticas o con principios no reductibles a fuentes sociale ${ }^{22}$. Todos coinciden en la tesis de Hart, según la cual el Derecho positivo ya no es el criterio público de obediencia, pues incluso las reglas vigentes -según criterios como las reglas de reconocimiento en el sentido de $\mathrm{Hart}^{23}$ - pueden ser desobedecidas: "esto es Derecho, pero demasiado inicuo para ser obedecido o aplicado" 24 . Naturalmente, no coinciden en cuanto al modo de esta integración de la moral crítica en el Derecho real, objetivo. Dworkin, en casos extremos, propone que el juez debe mentir ${ }^{25}$. MacCormick muestra, acertadamente en mi opinión, que muchos principios jurídicos son variables en el tiempo, tienen una historia de descubrimiento, aplicación y vigencia, y de extinción ${ }^{26}$. Sin embargo, algunos reflejan exigencias permanentes de justicia, como el principio del razonamiento "consecuencialista" -tener en cuenta que su decisión actual lo compromete para el futuro y considerar, entonces, las consecuencias generales de la regla establecida $-{ }^{27}$ o el

${ }^{20}$ Cfr. MacCormick, Neil, Legal Reasoning and Legal Theory (Oxford, Oxford University Press, 1997, con nuevo prefacio de 1994), pp. xiv-xv.

${ }^{21}$ Cfr. Dworkin, Ronald, Los derechos en serio (traducción castellana, Barcelona, Ariel, 1984). Antes, Joseph Esser, Principio y norma en la elaboración jurisprudencial del Derecho privado (Barcelona, Bosch, 1961).

${ }^{22}$ Sobre las diversas tesis recientes acerca de los principios, véase: ALEXY, Robert, El concepto y la validez del Derecho (Barcelona, Gedisa, 1994), pp. 161 ss. y 184-186; MacCormick, Neil, Legal Reasoning and Legal Theory, cit. (n. 20), pp. 152-156; FINNIS, John, Ley natural y derechos naturales, cit. (n. 9), pp. 94-96.

${ }^{23}$ Cfr. Hart, H. L. A., The Concept of Law, cit. (n. 4), pp. 97-120.

${ }^{24}$ Ibíd., p. 205. Véase también Raz, Joseph, The Authority of Law. Essays on Law and Morality (Oxford, Oxford University Press, 1979), pp. 232-236, 261, 289.

${ }^{25}$ Dworkin, Ronald, Los derechos en serio, cit. (n. 21), pp. 450-451. En DworKIN, Ronald, El imperio de la justicia (traducción castellana de Claudia Ferrari, Gedisa, Barcelona, 1988), pp. 284 ss., también reconoce este autor la distancia entre lo que exigiría la justicia en una interpretación pura y la respuesta correcta según las exigencias y restricciones del sistema jurídico.

${ }^{26}$ Cfr. MacCormick, Neil, Legal Reasoning and Legal Theory, cit. (n. 20), pp. 223-224 y 235-239.

${ }^{27}$ Ibíd., pp. 129 ss. No se trata del "consecuencialismo" tal como se entiende en el debate metaético y teológico moral contemporáneo. Véanse: John FinNis, Absolu- 
principio de que el juez debe empeñarse en que su decisión sea coherente con el resto del sistema ${ }^{28}$. John Finnis, como representante actual de la tradición clásica de la teoría de la ley natural, expone una concepción de los principios jurídicos como principios de segundo orden, racionalmente conectados con los principios puramente morales, pero no deducidos de ellos $^{29}$. Robert Alexy, en fin, reconoce que los argumentos a partir de un sistema axiológico-teleológico "juegan, tanto en la praxis judicial como también en la de la ciencia jurídica, un papel importante" ${ }^{30}$; sin embargo, sostiene que "esta argumentación no tiene un carácter concluyente" ${ }^{31}$. La argumentación jurídica justifica externamente premisas del razonamiento jurídico que no son ni enunciados empíricos ni reglas de Derecho positi$\mathrm{vo}^{32}$. Además, los principios intervienen especialmente en la interpretación teleológica del Derecho positivo ${ }^{33}$.

Al parecer, pues, manteniéndonos en el plano de la explicación conceptual del fenómeno jurídico -sin descender a discusiones concretas sobre qué reglas serían justas o injustas-, podemos concluir que la comprensión del Derecho tal como es exige considerar el punto de vista interno del juez que procura hacer justicia de manera imparcial, objetiva. No negamos que sea posible, en muchos contextos, una descripción de normas con anterioridad a su crítica. La labor cotidiana del jurista, del político, del reformador del Derecho, contiene muy a menudo semejantes descripciones, seguidas de su crítica. Tampoco negamos que tenga sentido el análisis general de los conceptos jurídicos, con independencia de las discusiones prácticas sobre cuestiones ético-jurídicas concretas. Es posible, por ejemplo, analizar los conceptos de obligación y de prohibición sin discutir si pagar tal tributo es obligatorio o si está prohibido fotocopiar libros. En ninguna parte de esta exposición abandonamos el terreno de la explicación conceptual sobre la objetividad del Derecho para pasar a una discusión justificatoria específi$\mathrm{Ca}^{34}$, sino que sostenemos que la comprensión de la realidad objetiva del

tos morales. Tradición, revisión y verdad (Barcelona, Ediciones Internacionales Universitarias, 1992), passim; y Ley natural y derechos naturales, cit. (n. 9), p. 161.

${ }^{28}$ Cfr. MacCormick, Neil, Legal Reasoning and Legal Theory, cit. (n. 20), pp. 152 ss.

${ }^{29}$ Cfr. FInNIS, John, Ley natural y derechos naturales, cit. (n. 9), pp. 313-317.

${ }^{30}$ AleXY, Robert, Teoría de la argumentación jurídica. La teoría del discurso racional como teoría de la fundamentación jurídica (Madrid, Centro de Estudios Constitucionales, 1997), p. 26.

${ }^{31}$ Ibíd.

${ }^{32}$ Ibíd., p. 222.

${ }^{33}$ Véase, con más detalle: OrRego, Cristóbal, De la ontología del Derecho al Derecho justo, cit. (n. 2), pp. 311-317.

${ }^{34}$ Agradezco al profesor Juan Vega, del Instituto de Investigaciones Jurídicas de 
Derecho, en el plano conceptual, exige vincular la objetividad abstracta de las normas con la objetividad concreta de los jueces. En definitiva, en la objetividad de los jueces -su imparcialidad, su justicia- se halla la condición de posibilidad de la objetividad del Derecho normativo tal como es. No podemos comprender el Derecho sin una teoría de la judicación, ni podemos comprender la judicación sin una teoría de la justicia.

[Recibido el 4 de mayo de 2009 y aceptado el 21 de septiembre de 2009].

\section{BIBLIOGRAFÍA}

AleXY, Robert, El concepto y la validez del Derecho (Barcelona, Gedisa, 1994).

AlEXY, Robert, Teoría de la argumentación jurídica. La teoría del discurso racional como teoría de la fundamentación jurídica (Madrid, Centro de Estudios Constitucionales, 1997).

AQuino, Tomás DE, Comentario a la Ética a Nicómaco.

ATRIA, Fernand, On Law and Legal Reasoning (Oxford, Hart Publishing, 2001).

Coleman, Jules - Shapiro, Scott (editores), The Oxford Handbook of Jurisprudence and Philosophy of Law (Oxford, Oxford University Press, 2002).

Dworkin, Ronald, Los derechos en serio (traducción castellana, Barcelona, Ariel, 1984).

EndicotT, Timothy, Law and Language, en Coleman, Jules - Shapiro, Scott (editores), The Oxford Handbook of Jurisprudence and Philosophy of Law (Oxford, Oxford University Press, 2002).

Esser, Joseph, Principio y norma en la elaboración jurisprudencial del Derecho privado (Barcelona, Bosch, 1961).

FinNIS, John, Absolutos morales. Tradición, revisión y verdad (Barcelona, Ediciones Internacionales Universitarias, 1992).

FinNis, John, Ley natural y derechos naturales (traducción castellana de Cristóbal Orrego, Buenos Aires, Abeledo-Perrot, 2000).

FinNIS, John, Natural Law and Legal Reasonin", en GeorGe, Robert P. (editor), Natural Law Theory. Contemporary Essays (New York, Oxford University Press, 1992).

Finnis, John, Natural Law: The Classical Tradition, en Coleman, Jules - Shapiro, Scott (editores), The Oxford Handbook of Jurisprudence and Philosophy of Law (Oxford, Oxford University Press, 2002).

GarCía Figueroa, Alfonso, Principios y positivismo jurídico. El no positivismo principialista en las teorias de Ronald Dworkin y Robert Alexy (Centro de Estudios Políticos y Constitucionales, Madrid, 1998).

GrISEZ, Germain, Beyond the New Theism: A Philosophy of Religion (Notre Dame, Ind., Notre Dame University Press, 1975).

la UNAM, sus observaciones sobre la distinción entre el análisis conceptual y el paso al discurso justificatorio, en línea con lo observado por HART, H. L. A., Post scriptum al concepto de Derecho, cit. (n. 11), pp. 11-18. 
Hart, H. L. A., Positivism and the Separation of Law and Morals, en Essays in Jurisprudence and Philosophy (Oxford, Oxford University Press, 1982).

Hart, H. L. A., Post scriptum al concepto de Derecho (editado por Penelope A. Bulloch y Joseph Raz, trad. cast. de Rolando Tamayo y Salmorán, México, D.F., UNAM, 2000).

Hart, H. L. A., The Concept of Law (Oxford, Clarendon Press, 1961).

Hervada, Javier, Lecciones propedéuticas de Filosofía del Derecho (Pamplona, Eunsa, 1992).

Himma, Kenneth Eina, Inclusive legal positivism, en Coleman, Jules - SHapiro, Scott (editores), The Oxford Handbook of Jurisprudence and Philosophy of Law (Oxford, Oxford University Press, 2002).

Kelsen, Hans, Teoría general de las normas (traducción castellana de Hugo Carlos Delory Jacobs, México D.F., Trillas, 1994).

Leiter, Brian, Law and Objectivity, en en Coleman, Jules - Shapiro, Scott (editores), The Oxford Handbook of Jurisprudence and Philosophy of Law (Oxford, Oxford University Press, 2002).

MacCormick, Neil, Legal Reasoning and Legal Theory (Oxford, Oxford University Press, 1997, con nuevo prefacio de 1994).

Marmor, Andrei, Exclusive legal positivism, en en Coleman, Jules - Shapiro, Scott (editores), The Oxford Handbook of Jurisprudence and Philosophy of Law (Oxford, Oxford University Press, 2002).

Orrego, Cristóbal, De la ontología del Derecho al Derecho justo. Progresos recientes de la teoría analitica del Derecho, en Revista Chilena de Derecho 30 (2003) 2.

Perelman, Chäim, La lógica jurídica y la nueva retórica (Madrid, Civitas, 1979).

Pound, Roscoe, Mechanical Jurisprudence, en Columbia Law Review 8 (1908).

RAz, Joseph, The Authority of Law. Essays on Law and Morality (Oxford, Oxford University Press, 1979).

Ross, Alf, El concepto de validez y el conflicto entre el positivismo jurídico y el Derecho natural, en Alf Ross, El concepto de validez y otros ensayos (México, D.F., Fontamara, 1993).

Ross, Alf, Hacia una ciencia realista del Derecho. Crítica del dualismo en el Derecho (trad. cast. de Julio Barboza, Buenos Aires, Abeledo-Perrot, 1961). 
